\title{
RELACIÓN ENTRE PRÁCTICAS ALIMENTARIAS REPORTADAS POR NIÑOS CHILENOS Y PREFERENCIAS DE LOS PADRES PARA SU CONSUMO
}

\author{
RELATIONSHIP BETWEEN REPORTED DIETARY \\ PRACTICES OF CHILEAN CHILDREN AND THEIR \\ PARENTS PREFERENCES FOR THEIR CONSUMPTION
}

\author{
Andrea J. Bankoski (1), Kathryn H. Jacobsen (1), Lisa R. Pawloski (1), \\ Jean Burley Moore (2), Kathleen F. Gaffney (2), Sonia Jaimovich (3), Cecilia Campos (3)
}

(1) Department of Global and Community Health, George Mason University, Fairfax, Virginia, USA.

(2) School of Nursing, George Mason University, Fairfax, Virginia, USA.

(3) Pontificia Universidad Católica de Chile, Santiago, Chile.

\begin{abstract}
The objective of this study was to examine agreement between parental preferences and self-reported food intake in Chilean children. In 2008, 152 pairs of 8 to 13 year old schoolchildren and their parents in Santiago were surveyed. Children self-reported their frequency of consumption of foods from various food groups. Parents reported how often they preferred their children to consume foods from these same food groups. Children reported consuming more sweets, high-calorie snacks, and fruit, and fewer grains than their parents reported preferring them to consume. Girls, 10 and 11 year olds, and children who watched television and used the computer for less than 2 hours per day had dietary patterns most closely aligned with their parents'reported preferences. Children's dietary reports generally follow parental preferences. Intervention programs should include programs that facilitate parental guidance and encourage children to make healthy food choices at home and in school.
\end{abstract}

Key Words: Chile child nutrition; dietary survey; parent-child relations; obesity.

Este trabajo fue recibido el 8 de Enero de 2010 y aceptado para ser publicado el 28 de Junio de 2010.

\section{INTRODUCTION}

Childhood and adolescent obesity are on the rise in populations worldwide, including in middle-income transition economies like Chile, which has experienced a steep increase in childhood overweight and obesity. [1] Between 1986 and 1998, the prevalence of obesity in Chile increased from $4 \%$ to $30 \%$ in 6 to 11 year old boys and from $2 \%$ to $15 \%$ in 12 to 16 year old adolescent boys; in girls, the prevalence of obesity rose from $5 \%$ to $24 \%$ in 6 to 9 year olds and $2 \%$ to $18 \%$ in 10 to 16 year olds girls.[2] Obesity in childhood is a precursor to adult obesity and associated chronic diseases such as diabetes, hypertension, cardiovascular disease, and cancer, [3] so failure to control childhood weight problems can lead to a less healthy adult population in a few decades. Children's food intake is one of the most important factors for controlling childhood weight problems and curbing rising obesity rates.

This study compares children's self-reported food intake to their parents' reported consumption preferences for their children. Parents play an important role in preventing childhood overweight and obesity. When parents model good dietary habits, encourage proper nutrition, and ensure that healthy foods are available and accessible in the home, children are more likely to consume nutritious foods. [4-7] Parental preferences are especially important because eating behaviors during childhood form habits and food choices that persist in adulthood [8].

The goal of this study was to explore the relationship between Chilean children's reported dietary practices and their parents' preferences for their consumption. 
The focus is on children in the developmental stages of intermediate childhood and preadolescence (children who are roughly 8 to 13 years old). This study is one of the few studies of child dietary behaviors in Chile, and is the first to examine the relationship between parental preferences and children's food choices.

\section{SUBJECTS AND METHODS}

Subjects. This cross-sectional study examined selfreported nutritional and health behaviors in children from Santiago, Chile, in June 2008. Schoolchildren were asked to complete a questionnaire about diet and health practices and to undergo anthropometric assessment, and their parents were asked to complete a similar survey on how often they prefer their children to consume certain types of foods.

Participating boys and girls attended one of two schools located in the middle-class suburbs of Santiago. One school is a private Montessori school on the north side of the city that enrolls students from preschool through secondary school. The other school is a public school on the south side of the city that enrolls elementary and middle school students. In both schools, all classrooms in which the school records showed that a majority of students were between 8 and 13 years old were invited to participate in the research project. A few students in some classes were outside the target age group, but the analysis presented in this paper is limited to child participants that were 8 to 13 years old.

Instruments. Both student and parent questionnaires asked about eight food categories: fruits, green vegetables, other vegetables, meat, milk, sweets, grains, and high-calorie snack foods (table 1). Children were asked how often they consumed these foods and parents were asked to indicate how often they preferred their children to consume these foods. Both questionnaires used a scale for reporting food frequency, with possible answers of not at all (coded as "1"), one to two times a week (2), once a day (3), twice a day (4), or three or more times a day (5). Parents were also asked to report on the actual daily hours of exercise, television watching, and computer use of their children. The survey instruments have been validated in preadolescent and adolescent populations in urban Chile[9].

Procedures. Consent forms and parental questionnaires were sent to the homes of all eligible students two weeks before the child survey date. Parents were asked to read a consent statement and sign it if they agreed to their children's participation, to complete the parental questionnaire, and to send the entire packet back to the school. Students whose parents had returned a signed consent form were asked to read and sign an assent form before completing their questionnaire. The children filled in the questionnaires in a private room during school hours. Researchers were available to assist younger students and those with questions about the survey instrument.

The heights and weights of each participating child were measured by trained professionals using standardized methods, [10] with children wearing light clothes and without shoes. Height was measured in centimeters using a GPM-brand field anthropometer and weight was measured with a portable digital scale (Tanita brand). Students were asked to assent to each

\section{TABLE 1}

\section{Questions for children and their parents.}

\section{For children}

Please answer the following questions according to how often you do the following activities:

- Eat fruits

- Eat green vegetables

- Eat other vegetables

- Eat meat

- Drink milk

- Eat sweets

- Eat cereal, bread, or tortillas

- Eat snacks that contain lots of calories

\section{For parents}

Please answer the following questions according to the frequency with which you encourage your son or daughter to do the following activities:

- Eat fruits

- Eat green vegetables

- Eat other vegetables

- Eat meat

- Drink milk

- Eat sweets

- Eat cereal, bread, or tortillas

- Eat snacks that contain lots of calories 
anthropometric measurement prior to being measured. Each child's BMI was calculated based on the height and weight measurements. Overweight was defined as a BMI between the 85 th and 95 th percentiles and obesity was defined as a BMI greater than the 95th percentile, which follow guidelines from the U.S. $\mathrm{CDC}$ [11]. (The CDC reference population is frequently used by nutrition studies in Chile). All measurements were taken with at least two adults present, but with no other students nearby so as to maintain the confidentiality and comfort of each student. An inexpensive pen was given as a gift to each participating student, and parents were provided with a list of the child's physical measurements and growth chart percentiles. The research protocol was approved by the Institutional Review Boards of both George Mason University (Fairfax, Virginia, USA) and Pontificia Universidad Católica de Chile (Santiago, Chile).

Data Analysis. Data were analyzed using SPSS 16.0 , and significance was set as $\alpha=0.05$. After conducting initial descriptive and comparative analysis of the demographics of the study population using chi-squared tests of distribution and independent samples t-tests for comparison of means, two main analyses of dietary attitudes and practices were conducted.

First, the difference in response between each pair of child and parent answers to a particular food frequency question was calculated. Each child's numeric response to a question was subtracted from the numeric response of the parent. For example, if a child reported eating fruits one to two times a week (2) and the parent said she or he preferred the child to eat fruit twice a day (4), then the score would be -2 . The negative sign indicates that the child reported consuming the food less often than preferred by the parent.

Second, a composite agreement score was calculated by taking the average of the absolute values of the eight pairs of questions for each child. For example, if the differences for the eight questions were $-2,-1,-1,0,0$, 1,3 , and 4 , then the summary score would be the sum of the absolute values (12) divided by eight, for a final score of 1.5. This means that for that child-parent pair, the average food frequency response differed by 1.5 . For the thirteen child-parent pairs for which one or more food scores were missing, the composite agreement score was determined by taking the average of the absolute values of the non-missing questions for each child. The composite agreement scores were compared for several demographic and other groups using chi-squared tests for trend and t-tests or ANOVA for comparison of means. ANCOVA was used for comparisons of the mean responses from the two schools so that an adjustment could be made for a slight age difference in the participants from the two schools.

\section{RESULTS}

Study Population. At the private Montessori school, 5 classrooms with a total of 155 students were invited to participate, and 104 (67\%) students returned a signed consent form and participated in at least part of the study. At the public school, 150 surveys were distributed, and 103 (69\%) students had parental consent and participated in at least part of the study. There was no difference in the participation rates of the two schools $(p=0.77)$. None of the parents of non-participants refused for their children to participate, but about one-third of students did not remember to give the paperwork to their parents or did not remember to return the signed documents to the school.

Of these 207 participating students, 190 (92\%) were between the ages of 8 and 13. This paper will focus on the $152(80.0 \%)$ children between the ages of 8 and 13 years old who completed at least $80 \%$ of the questionnaire, had both their height and weight measured, and had parents who returned a questionnaire that was at least $80 \%$ complete.

In total, 74 (49\%) of these 152 children attended the private Montessori school and $78(51 \%)$ children attended the public school. There were no differences in the distribution of students by sex $(\mathrm{p}=0.79$, with $59 \%$ females at the private school and $62 \%$ females at the public school). Students at the private school were slightly younger (mean age of 10.9 vs. 11.4 years old, $\mathrm{p}=0.05$ ). The overall prevalence of overweight and obesity was $38 \%$. After adjusting for age differences at the two schools there were no differences in the prevalence of overweight/obesity ( $32 \%$ vs. $42 \%, \mathrm{p}=0.25$ ), mean weekly hours of physical activity ( 5.5 vs. $3.9, \mathrm{p}=0.74)$, mean hours of daily television viewing ( 1.7 vs. $2.5, \mathrm{p}=0.65)$, or mean hours of daily computer use (1.3 vs. $1.2, \mathrm{p}=0.26)$. The responses to the food frequency questionnaire for children were not statistically different between the schools. Because the students from both schools were so similar, as shown by these statistical tests, students from both schools will be grouped in this analysis.

The primary purpose of this paper is to compare child self-reports of food consumption to parental preferences for how often their children eat from the various food groups. The vast majority (143 of 152) of the parental surveys were completed by mothers. Parents were more likely to return surveys if their child was a younger student (mean age 11.0 vs. 11.9 years, $p<0.01$ ), but there were no differences in response based on the sex of the child ( $\mathrm{p}=0.08)$ or the child's BMI ( $\mathrm{p}=0.50)$. 
Physical activity levels, television watching, and computer use were only reported by parents and were therefore missing for parental non-responders. The children whose parents returned completed surveys reported that they ate grains less frequently than children whose parents did not return complete surveys ( $\mathrm{p}=0.03$ ); student responses to the other food groups were not different.

Of the 152 child participants, $92(61 \%)$ were female and $60(39 \%)$ were male. The average age of children answering the questionnaire was 11.0 (1.4); 49 (32\%) children were 8 or 9 years old, $60(39 \%)$ were 10 or 11 years old, and $43(28 \%)$ were 12 or 13 years old. In total, $95(63 \%)$ children were classified as average weight and $57(38 \%)$ children were classified as overweight or obese. Based on parental reporting, 77 (51\%) children were physically active less than five hours per week, 97 (64\%) children watched television for two or more hours per day, and $28(18 \%)$ children used the computer for two or more hours per day.

Food consumption. Table 2 shows mean child and parent responses to dietary questions. Parents reported preferring their children to consume milk (average response of 3.72), fruit (3.52), grains (3.46), green vegetables (3.23), and non-green vegetables (3.09) more often than the other three food groups. The foods reported by children as being consumed most frequently were fruit
(3.79), milk (3.64), non-green vegetables (3.17), grains and cereals (3.09), and green vegetables (3.05). Children and parents both reported less frequent consumption of or preference for, respectively, meat (2.47 and 2.56), sweets (1.87 and 2.40), and high-calorie snacks (1.76 and 2.25). Despite this agreement on the relative consumption of foods from the eight food groups, children reported eating sweets $(\mathrm{p}<0.01)$, high-calorie snacks $(\mathrm{p}<0.01)$, and fruit $(\mathrm{p}=0.01)$ more frequently than their parents preferred, and consuming grains less frequently than preferred by parents $(\mathrm{p}<0.01)$. The reported and preferred frequencies of food consumption of children and parents, respectively, were not statistically different for milk, non-green vegetables, meat, and green vegetables.

Child-Parent agreement. Table 3 shows the results of the composite agreement score (CAS) described in the methods section. It summarizes the average agreement between each child-parent pair over all eight food groups combined. Significant differences in agreement were observed for the CAS. Girls reported values closer to their parents than boys (CAS of 0.89 vs. $1.04, \mathrm{p}=0.02$ ). With regard to age, 10 and 11 year olds had significantly closer agreement with parents (0.85) than either younger students (1.00 for 8 and 9 year olds) or older students ( 1.04 for 12 to- 13 year olds, $\mathrm{p}=0.03$ ). Children who were reported to watch television for less than 2 hours per day

\section{TABLE 2}

Agreement between child reports and parental preferences.

\begin{tabular}{|c|c|c|c|c|c|c|c|}
\hline \multirow[b]{2}{*}{$\begin{array}{l}\text { Food } \\
\text { Category }\end{array}$} & \multirow[b]{2}{*}{$\begin{array}{l}\text { Mean child } \\
\text { response for } \\
\text { reported } \\
\text { consumption }\end{array}$} & \multirow[b]{2}{*}{$\begin{array}{l}\text { Mean parent } \\
\text { response for } \\
\text { preferred child } \\
\text { consumption }\end{array}$} & \multirow[b]{2}{*}{$\begin{array}{c}\text { Mean } \\
\text { difference }\end{array}$} & \multirow[b]{2}{*}{$\begin{array}{c}\text { p-value for } \\
\text { matched-pairs } \\
\text { t-test }\end{array}$} & \multicolumn{3}{|c|}{$\begin{array}{l}\text { Child-Paren Agreement } \\
\text { (number of pairs) }\end{array}$} \\
\hline & & & & & $\begin{array}{l}\text { Child reports } \\
\text { eating less than } \\
\text { the parent prefers } \\
\text { (negative) }\end{array}$ & Equal & $\begin{array}{l}\text { Child reports } \\
\text { eating more than } \\
\text { the parent prefers } \\
\text { (positive) }\end{array}$ \\
\hline $\begin{array}{l}\text { Sweets } \\
\text { High-Calorie }\end{array}$ & 2.40 & 1.87 & 0.53 & $<0.01 *$ & 23 & 61 & 68 \\
\hline Snacks & 2.25 & 1.76 & 0.49 & $<0.01 *$ & 31 & 51 & 74 \\
\hline $\begin{array}{l}\text { Fruit } \\
\text { Non-Green }\end{array}$ & 3.79 & 3.52 & 0.27 & $0.01 *$ & 34 & 56 & 66 \\
\hline Vegetables & 3.17 & 3.09 & 0.08 & 0.49 & 55 & 43 & 55 \\
\hline Meat & 2.56 & 2.47 & 0.09 & 0.33 & 41 & 71 & 44 \\
\hline $\begin{array}{l}\text { Milk } \\
\text { Green }\end{array}$ & 3.64 & 3.72 & -0.08 & 0.42 & 45 & 67 & 44 \\
\hline Vegetables & 3.05 & 3.23 & -0.18 & 0.13 & 63 & 50 & 43 \\
\hline Grains & 3.09 & 3.46 & -0.37 & $0.01 *$ & 72 & 38 & 41 \\
\hline
\end{tabular}


had lower CAS values than children who were reported to watch more television ( 0.85 vs. $1.00, \mathrm{p}=0.04)$, and children who were reported to spend less than 2 hours a day using the computer had lower CAS values than children who were reported to spend more time on the computer ( 0.90 vs. $1.09, \mathrm{p}=0.02)$. Differences in the CAS were not observed for BMI group ( $\mathrm{p}=0.22$ ) or the child's reported physical activity level $(\mathrm{p}=0.82)$.

\section{DISCUSSION AND CONCLUSIONS}

Key findings. This is one of the first studies to examine the relationship between parental preferences toward their children's dietary practices, and one of the first studies to examine dietary behavior among children in Chile. Children in this study reported consuming fruit, milk, non-green vegetables, grains, and green vegetables more frequently than meat, sweets, and high-calorie snacks. This reported frequency of consumption was fairly close to parental preferences for their children's consumption of these food groups, although children ate more meat, sweets, and high-calorie snack foods than preferred by parents. Children who were female, 10 or 11 years old (rather than younger or older), and spent less than two hours a day watching television or using the computer reported consumption frequencies closest to their parents' preferences.

Comparison to previous studies. These results on food consumption reported by the Chilean children were generally similar to previous studies from other countries that have reported on dietary consumption in 8 to 13 year olds,[12-14] although children from this study reported a higher frequency of consumption of produce $[8,15-18]$ than some of the previous studies and a slightly higher consumption of snacks and sweets[18] than one previous study. Separating out green and nongreen vegetables in the Chile questionnaire might have increased total vegetable consumption reported by the study children. Most studies of child dietary practices focus on snacks and sweets, fruits, and vegetables; few studies have evaluated consumption of milk, meat, and grains. However, our general agreement with previous studies on the relative frequency of consumption provides support for the validity of our findings.

This study found that children who watched more television and spent more time using the computer consumed food with a greater frequency than preferred by parents. Previous studies have similarly found that children with more daily "screen time" make poorer

\section{TABLE 3}

Composite Agreement Score between child reports and parental preferences by demographics.

\begin{tabular}{|c|c|c|c|}
\hline & & $\begin{array}{l}\text { Composite Agreement Score } \\
\text { [mean (standard deviation)] }\end{array}$ & $\begin{array}{l}\text { p-value for test } \\
\text { of difference }\end{array}$ \\
\hline Total & & $0.95(0.40)$ & -- \\
\hline \multirow[t]{2}{*}{ Sex } & Female & $0.89(0.37)$ & $0.02 *$ \\
\hline & Male & $1.04(0.42)$ & \\
\hline \multirow[t]{3}{*}{ Age } & $8-9$ & $1.00(0.39)$ & $0.03 *$ \\
\hline & $10-11$ & $0.85(0.31)$ & \\
\hline & $12-13$ & $1.04(0.48)$ & \\
\hline \multirow[t]{2}{*}{ BMI } & Average & $0.92(0.38)$ & 0.22 \\
\hline & Overweight/Obese & $1.00(0.43)$ & \\
\hline \multirow[t]{2}{*}{ Physical Activity (hours per week) } & Less than $5 \mathrm{hrs}$ & $0.94(0.38)$ & 0.82 \\
\hline & $5 \mathrm{hrs}$ or more & $0.92(0.41)$ & \\
\hline \multirow[t]{2}{*}{ TV (hours per day) } & Less than 2 hrs & $0.85(0.31)$ & $0.04 *$ \\
\hline & $2 \mathrm{hrs}$ or more & $1.00(0.42)$ & \\
\hline \multirow[t]{2}{*}{ Computer Use (hours per day) } & Less than 2 hrs & $0.90(0.37)$ & $0.02 *$ \\
\hline & $2 \mathrm{hrs}$ or more & $1.09(0.42)$ & \\
\hline
\end{tabular}


food choices and have an increased caloric intake, a higher rate of obesity, and less physical activity[19,20], and have noted that boys and children from lower socioeconomic status may be at increased risk of television-related obesity [21]. Given that children who adhere to their parents' preferences for dietary choices generally have parents who create a healthy home food environment, [4,16-18] one approach that is likely to improve child nutritional status in at-risk populations is the implementation of nutritional interventions that aim to increase congruency of child eating patterns with parental dietary preferences $[22,23]$. For example, children who report that their parents demand that they eat fruits and vegetables also usually report having fruits and vegetables available in the home for snacking $[4,16]$. This is a relatively simple action parents can be encouraged to take to promote healthy diets for their children. In this study, the children who would benefit most from actions to promote healthy food choices are boys and children with a high frequency of "screen time."

Limitations. The main concern with this study is that all dietary information was self-reported, which could have introduced information bias. First, parents may have selected the answers they thought were "correct" rather than accurately recording their true nutrition preferences for their children. This is not likely to be a significant problem since previous studies have found parents to be valid sources in reporting their child's nutritional behaviors $[14,15]$, and are likely to be equally accurate in reporting their own preferences. Second, children could have selected more favorable answers rather than accurately reporting their food consumption. However, the agreement between this study and previous studies of food consumption among children in this age group make it unlikely that significant bias occurred. Third, it may be difficult for children to accurately report their own food consumption. Previous studies have found that children may make potential errors in self-reports by under-reporting, over-reporting, and incorrectly identifying food items and portions [24,25]. However, these same studies that shown that by 7 or 8 years of age - the youngest ages of children in the Chile study population - most children have developed the ability to make accurate self-reports. [24,25] To further minimize concern about potential error associated with the estimation of portion sizes, the questionnaire used in Chile asked for the frequency of consumption rather than amount eaten[24]. Thus, information bias is unlikely to be a significant problem in this study.

Conclusion. This study is one of the few assessments of child dietary practices in Chile. Children in this study reported consuming foods with a similar frequency as preferred by their parents. This high level of agreement between children and their parents was true for both students from a private school and students from a public school. Because studies - including this one - consistently show that parents have a significant impact on their children's dietary practices, nutrition education programs that alert parents to the need to encourage healthy nutritional behaviors in their children may contribute to slowing the rise in the prevalence of obesity in children and early adolescents. Schools can play a key role in health promotion by providing information about nutritious food choices to both students and their parents.

\section{RESUMEN}

Se estudia concordancia entre preferencias de padres y auto-reporte de niños chilenos en consumo de alimentos. En 2008, se encuestaron 152 escolares ente 8 y 13 años de edad y sus padres, en Santiago, Chile. Los niños reportaron frecuencia de consumo de diferentes grupos de alimentos y los padres, frecuencia con que prefieren que sus hijos los consuman. Los niños informaron mayor consumo de dulces, colaciones altas en calorías y frutas y menor consumo de cereales, que lo declarado por sus padres. Los patrones alimentarios más estrechamente alineados con lo reportado por los padres se observan en: niñas; edades entre 10 y 11 años; ver televisión y utilizar computador menos de 2 horas diarias. En general, lo reportado por niños sigue los patrones de los padres. Programas de intervención debieran incluir guía a padres y estimulo a niños para elegir opciones alimentarias saludables en el hogar y en la escuela.

Dirigir la correspondencia a:

Profesora

María Cecilia Campos

Pontificia Universidad Católica de Chile

Avenida Vicuña Mackenna 4860 - Macul

Santiago, Chile

Teléfono: 56-2-354-5839

Fax: 56-2-354-7025

Email: ccampos@uc.cl

\section{REFERENCES}

1. Uauy R, Albala C, Kain J. Obesity trends in Latin America: transiting from under- to overweight. J Nutr. 2001;131:893-9.

2. Muzzo S, Burrows R, Cordero J, Ramírez I. Trends in nutritional status and stature among school-age children in Chile. Nutrition. 2004;20:867-72.

3. Magarey A, Daniels L, Boulton T, Cockington R. Predicting obesity in early adulthood from child- 
hood and parental obesity. Int J Obes Related Metab Disord. 2003;27:505-13.

4. Pearson N, Biddle S, Gorely T. Family correlates of fruit and vegetable consumption in children and adolescents: a systematic review. Public Health Nutrition. 2008;1-17.

5. Rasmussen M, Krolner R, Klepp KI, et al. Determinants of fruit and vegetable consumption among children and adolescents: a review of the literature. Part I: quantitative studies. Int J Behav Nutr Phys Act. 2006;3:22.

6. Blanchette L, Brug J. Determinants of fruit and vegetable consumption among 6-12-year-old children and effective interventions to increase consumption. J Hum Nutr Diet. 2005;18:431-43.

7. Bere E, Klepp KI. Correlates of fruit and vegetable intake among Norwegian schoolchildren: parental and self-reports. Public Health Nutr. 2004; 7: 991-98.

8. Gibson E, Wardle J, Watts C. Fruit and vegetable consumption, nutritional knowledge and beliefs in mothers and children. Appetite. 1998;31:205-28.

9. Jaimovich S, Campos MC, Campos MS, Moore JB. Spanish version of the Child and Adolescent SelfCare Performance Questionnaire: psychometric testing. Pediatr Nurs. 2009;35:109-14.

10. Lohman TG, Roche AF, Martorell R. Anthropometric Standardization Reference Manual. Chicago, IL: Human Kinetics Books; 1988.

11. Kuczmarski RJ, Ogden CL, Grummer-Strawn LM, et al. CDC growth charts: United States. Advance data from vital and health statistics. Hyattsville, MD: National Center for Health Statistics; 2000; no. 314.

12. Ayala G, Baquero B, Arredondo E, et al. Association between family variables and Mexican American children's dietary behaviors. J Nutr Educ Behav. 2007;3962-69.

13. Tak NI, te Velde SJ, de Vries JHM, Brug J. Ethnic differences in 1-year follow-up effect of the Dutch schoolgruiten project - promoting fruit and vegetable consumption among primary-school children. Public Health Nutr. 2008;10:1497-507.

14. Tak NI, te Velde SJ, de Vries JHM, Brug J. Parent and child reports of fruit and vegetable intakes and related family environmental factors show low levels of agreement. J Hum Nutr Diet. 2006;19:275285.

15. Reinaerts E, de Nooijer J, de Vries NK. Parental versus child reporting of fruit and vegetable consumption. Int J Behav Nutr Phys Act. 2007;4:33.

16. Kristjansdottir AG, Thorsdottir I, De Bourdeaudhuij I, et al. Determinants of fruit and vegetable intake among 11-year-old schoolchildren in a country of traditionally low fruit and vegetable consumption. Int J Behav Nutr Phys Act. 2006;3:41.

17. Wind M, de Bourdeaudhuij I, Te Velde SJ, et al. Correlates of fruit and vegetable consumption among 11-year-old Belgian-Flemish and Dutch schoolchildren. J Nutr Educ Behav. 2006;38:211-21.

18. Matheson DM, Robinson TN, Varady A,Killen JD. Do Mexican-American mothers' food-related parenting practices influence their children's weight and dietary intake? J Am Diet Assoc. 2006;106:1861-5.

19. Wiecha J, Peterson K, Ludwig D, et al. When children eat what they watch. Arch Pediatr Adolesc Med. 2006;160:436-42.

20. Andersen R, Crespo C, Bartlett S, Cheskin L, Pratt M. Relationship of physical activity and television watching with body weight and level of fatness among children: Results from the Third National Health and Nutrition Examination Survey. JAMA. 1998;279:938-42.

21. Vereecken C, Todd J, Roberts C, Mulvihill C, Maes L. Television viewing behaviour and associations with food habits in different countries. Public Health Nutr. 2005;9:244-50.

22. Harnack L, Himes J, Anliker J, et al. Interventionrelated bias in reporting of food intake by fifth-grade children participating in an obesity prevention study. Am J Epidemiol. 2004;160:1117-21.

23. Coon KA, Tucker KL. Television and children's consumption patterns. A review of the literature. Minerva Pediatr. 2002;54:423-36.

24. Livingstone M, Robson P, Wallace J. Issues in dietary intake assessment of children and adolescents. Br J Nutr. 2004;92:S213-S22.

25. Livingstone M, Robson P. Measurement of dietary intake in children. Proc Nutr Soc. 2000;59:279-93. 